\title{
High performance flat miniature heat pipes fabricated by UD-LIGA process
}

\author{
Y. Cheng, P. P. Ding, T. S. Sheu, B. Y. Shew, P. H. Chen
}

Abstract The objective of this work is to process a high performance flat miniature heat pipes (FMHP). The FMHP is fabricated by ultra-deep LIGA (UD-LIGA) process developed by SRRC. Moreover, the performance of the FMHP is theoretically estimated. The dimensions of microgrooves on the FMHP are $1 \mathrm{~mm}$ in depth, $100 \mu \mathrm{m}$ in width, and $60 \mathrm{~mm}$ in length. The theoretically predicted results show that the dissipated heat flux can reach to $391 \mathrm{~W}$ at a working temperature of $100{ }^{\circ} \mathrm{C}$.

\section{1}

\section{Introduction}

Recent trends in the electronic industry are to miniaturize components and to increase heat dissipation rate of devices. According to the prediction of Tadayon (2000), the microprocessor power is expected to reach $200 \mathrm{~W}$ within the next 5 years with a high average power density of $125 \mathrm{~W} / \mathrm{cm}^{2}$. Therefore, temperature control has become a critical factor in the design of any electronic equipment in the future. Heat pipe is a kind of heat sink that has better performance for electronic equipment cooling nowadays. The performance of heat pipes depends on the wick structure. Therefore, the design of wick structure is very important in increasing the heat dissipation rate. However, the wick manufacture technology at present cannot satisfy the rapid development of the electronic industry. The microgrooves of the present FMHP is fabricated by UD-LIGA process. The UD-LIGA process is able to produce an ultra deep microstructure with high aspect ratio (Cheng et al., 1999). This is advantageous to promote the permeability and the capillary performance of the FMHP.

Received: 10 August 2001/Accepted: 24 September 2001

Y. Cheng ( $₫)$, B. Y. Shew

Synchrotron Radiation Research Center,

Taiwan, ROC

\section{P. P. Ding, T. S. Sheu, P. H. Chen}

Department of Mechanical Engineering,

National Taiwan University,

Taiwan, ROC

This paper was presented at the Fourth International Workshop on High Aspect Ratio Microstructure Technology HARMST 2001 in June 2001.
2

\section{The UD-LIGA process}

The initial stage of the UD-LIGA process is to prepare a sandwich structure with a copper sheet, a PMMA sheet of designed thickness $(1 \mathrm{~mm})$ and an aluminum sheet (Cheng et al., 1999). A conformal mask is used in the process. The key processes are the UV lithography and the plating of gold absorber. The gold absorber is plated on a copper base attached directly to the thick X-ray photoresist (PMMA). By employing a successive exposure and development process, microgrooves structure of $1 \mathrm{~mm}$ deep $\left(d_{g}\right), 100 \mu \mathrm{m}$ wide $\left(2 w_{g}\right)$, and $60 \mathrm{~mm}$ long were successfully fabricated for the FMHP (Fig. 1). Figure 2 shows the prototype of FMHP formed by $\mathrm{Ni}$ electroforming process $(2 \mathrm{~mm}$ thick, $1.8 \mathrm{~mm}$ wide, and $60 \mathrm{~mm}$ long).

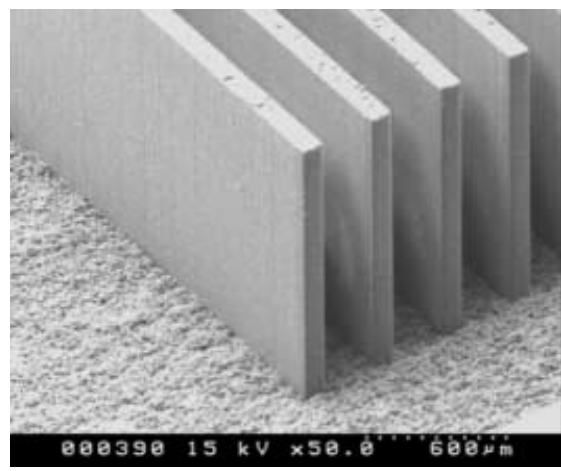

Fig. 1. The microgrooves structure for FMHP: $1 \mathrm{~mm}$ deep, $100 \mu \mathrm{m}$ wide, and $60 \mathrm{~mm}$ long (fabricated by UD-LIGA process)

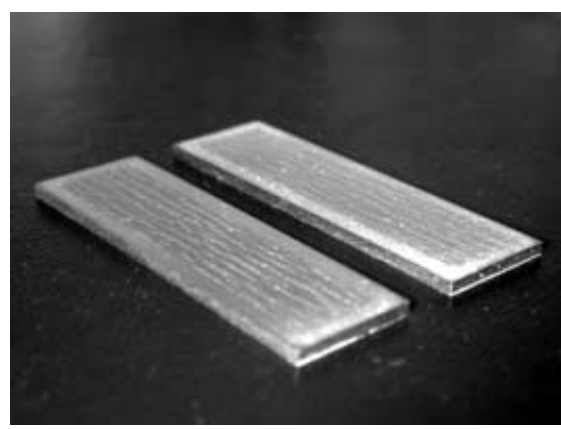

Fig. 2. The prototype of FMHP formed by Ni electroforming ( $2 \mathrm{~mm}$ thick, $1.8 \mathrm{~mm}$ wide, and $60 \mathrm{~mm}$ long) 

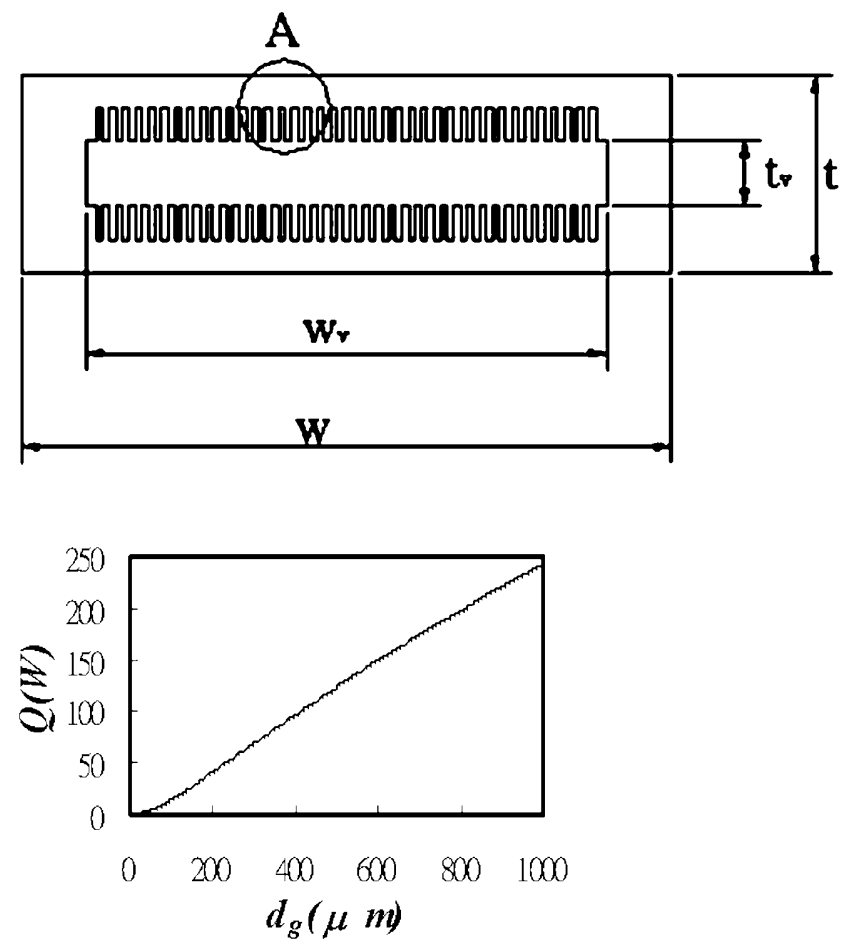

Fig. 4. The effect of microgrooves depth on the maximum heat transfer rate of the microgrooves structure

\section{3}

\section{Theoretical analysis}

The cross-sectional dimensions of FMHP are shown in Fig. 3. The work of Cao et al. (1997) describes the theoretical model of FMHP. The main factors are the depth and the width of microgrooves. Figure 4 shows the effect of microgrooves depth on the maximum heat transfer rate $(Q)$ for the microgrooves structure fabricated by UD-LIGA process. The depth of microgrooves is $1 \mathrm{~mm}$, the width of fin $\left(w_{f}\right)$ is $200 \mu \mathrm{m}$, and the length

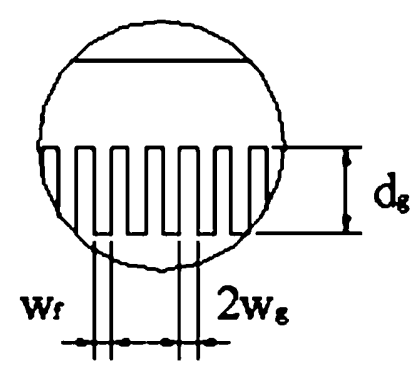

Detial A
Fig. 3. The cross-sectional dimensions of FMHP is $60 \mathrm{~mm}$. As shown in the figure, the maximum heat transfer rate is increasing with the increased microgrooves depth. Therefore, the high aspect ratio of microgrooves fabricated by the UD-LIGA process is effective in promoting the performance of FMHP. The maximum heat transfer rate can reach to value of $391 \mathrm{~W}$ at a working temperature of $100{ }^{\circ} \mathrm{C}$.

\section{4}

\section{Conclusions}

The present theoretical analysis proved that the FMHP fabricated by the UD-LIGA fabrication process has higher heat transfer rate. Therefore, this high performance FMHP is applicable to the cooling of electronic equipment with high heat dissipation rate.

\section{References}

Tadayon P (2000) Thermal challenges during microprocessor testing. Intel Tech J Q3

Cheng Y; Shew BY; Lin CY; Wei DH; Chyu MK (1999) Ultra-deep LIGA process. J Micromech Microeng 9: 58-63

Cao Y; Gao M; Beam JE; Donovan B (1997) Experiments and analyses of flat miniature heat pipes. J Thermophys Heat Transfer 11(2): 158-164 